\title{
MAIN CHARACTER IN THE NOVEL DI BIBIRNYA ADA DUSTA BY MIRA WIJAYA LIES AND THEIR IMPLICATION FOR INDONESIA LEARNING
}

\author{
Sri Mulyani \\ Universitas Indraprasta PGRI \\ Jl. Nangka No. 58C Tanjung Barat, Jagakarsa, Jakarta Selatan, Kode Pos, Indonesia \\ e-mail: srimulyani.unindra@gmail.com
}

\begin{abstract}
This study aims to describe the main character in the novel Di Bibirnya Ada Dusta. The method used for research was descriptive qualitative method. To analyze the data, researchers used analytic and dramatic approaches, Semi (in Djojosuroto, 2009: 119). Analytic approach was an approach that describes the character or character by describing the character directly, while the dramatic approach was the approach used by the author in describing the character indirectly. The technique of collecting data in this research is first reading the novel carefully, then marking the parts related to the analytic and dramatic aspects of the main character, the focus of the research, namely the novel Di Bibirnya Ada Dusta by Mira Wijaya, while the became a research sub-focus related to the attitudes and actions of the main characters. After researching it can be concluded, the main character in this novel, namely Ray and Roy. Ray's attitude can be seen from an analytical aspect, which is serious and a liar, while the dramatic attitude depicts Ray's physical athletic, macho, handsome, handsome, and intelligent, while Roy has a physical similar to Ray's when viewed in dramatic terms, namely handsome, macho, intelligent, athletic, and imaginative, while the analytical aspects of Roy's attitude, namely boredom, imaginative, brave, and liar. The results of this study will be used to provide teaching in Indonesian language and literature. With the aim, so students can enhance appreciation, be able to appreciate, and be able to recognize the character of the character that the author has described.
\end{abstract}

Keywords: Character, Novel, and Literature Learning.

Article History: Received: 31/05/2020; Revised: 19/06/2020; Accepted: 26/06/2020; Published: 16/07/2020

How to Cite (MLA 7th): Mulyani, Sri. "Main Character in The Novel Di Bibirnya Ada Dusta by Mira Wijaya Lies and Their Implication for Indonesia Learning." Hortatori Jurnal Pendidikan Bahasa dan Sastra Indonesia, vol. 4, no. 1, 2020, 48-56. Print/Online. Copyrights Holder: Sri Mulyani. First Publication: Hortatori Jurnal Pendidikan Bahasa dan Sastra Indonesia (2020).

This work is licensed under a Creative Commons Attribution-ShareAlike 4.0 International License.

\section{Pendahuluan}

Sebuah cerita tidak dapat bergerak tanpa adanya tokoh. Tokoh dalam suatu cerita merupakan hal yang sangat penting. Tokoh dalam cerita mempunyai peran berbeda-beda, tokoh yang menjadi pusat perhatian atau sering muncul disebut tokoh utama atau tokoh sentral. Tokoh yang kehadirannya hanya sebagai pelengkap disebut tokoh bawahan atau tokoh tambahan (periferal). Menurut Sujiman (1992: 16) tokoh utama adalah tokoh yang memegang peranan penting disebut tokoh utama atau protagonis. Tokoh ini merupakan tokoh yang menjadi pusat sorotan. Kriteria yang digunakan untuk menentukan tokoh bukan utama, yaitu frekuensi kemunculan tokoh itu dalam cerita, melainkan keterlibatan tokoh di dalam peristiwa-peristiwa yang membangun cerita, karena tokoh-tokoh itu rekaan pengarang, hanya pengaranglah yang mengenal mereka. Maka tokoh-tokoh itu perlu digambarkan ciri-ciri lahir, sifat, dan sikap batinnya agar wataknya dikenal oleh pembaca. 
Menurut Sujiman, watak atau karakter adalah berkaitan dengan kualitas tokoh, nalar, dan jiwa yang membedakan dengan tokoh lain. Semi (1988: 3) mengatakan watak adalah suatu aksi dan perilaku atau tindak tanduk. Masalah perwatakan atau karakter memegang peranan dalam suatu cerita. Pelukisan karakter yang baik, si pengarang menggambarkan dalam setiap tahap dalam ceritanya, sehingga pembaca melihat jelas watak pelakunya melalui semua tindak-tanduknya dan sikap-sikapnya.

Menurut Jakob (1997: 144) untuk mengenal karakter tokoh suatu cerita berdasarkan pada: 1) apa. 1) cakapan, 2) pikiran tokoh, 3) perbuatan tokoh, 4) sikap tokoh, 5) pandangan seseorang, 6yang diperbuat sang tokoh, 2) ucapan sang tokoh, 3) penggambaran tokoh, 4) melalui pikiran-pikiran, dan 5) penerangan langsung. Demikian juga Tasrip (dalam Djojosuroto, 2009: 122) menganalisis karakter dengan cara 1) melukiskan fisik, 2) mengenalkan pelaku, 3) mengenali reaksi pelaku melalui kejadiankejadian, 4) mengetahui pandangan pelaku dengan tokoh lain. Walaupun pengarang sudah menggambarkan watak-watak tokoh secara jelas, namun nyatanya, kebanyakan pembaca belum memahami sepenuhnya tentang karakter para tokoh dalam novel terutama yang berkaitan dengan sikap, tindak-tanduk atau dari pendekatan analitik dan dramatik. Oleh karena itu, salah satu daya tarik suatu cerita terletak pada saat pembaca mengenal tokoh cerita dalam kehidupannya. Semi (dalam Djojosuroto, 2009: 119) menjelaskan bahwa untuk mengenalkan perwatakan tokoh, pengarang mengenalkan melalui pendekatan analitik dan dramatik. Pendekatan analitik adalah pendekatan yang mengambarkan watak atau tokoh dengan mendeskripsikan sifat watak tokoh secara langsung, yaitu bisa diwujudkan seperti keras hati, keras kepala, penyayang, dsb., sedangkan pendekatan dramatik adalah pendekatan yang digunakan untuk mengambarkan tokoh secara tidak langsung. Namun, bisa disampaikan melalui pilihan nama, penggambaran fisik atau postur tubuh, cara berpakaian, melalui dialog.

Dengan demikian kajian yang relevan dengan penelitian ini, yaitu 1) Analaisis Karakter Tokoh Utama dalam Novel Lolita KaryaVladimir Nabokov yang diteliti oleh Jein Jeyklin Byl tahun 2016, Universitas Sam Ratungi Manado. Berdasarkan hasil penelitian yang Lolita lakukan, terkait dengan karakter Humbert, yaitu imajinasi, kesopanan, posesif, cerdik, tenang, dan hemat. Peneliti juga menemukan beberapa faktor yang memengaruhi perkembangan karakter tokoh utama Humbert, yaitu faktor dalam dan faktor dari luar. Faktor dari dalam terkait dengan masa lalu, pengendalian diri, dan cinta, sedangkan faktor dari luar terkait dengan informasi seksual dan kebiasaan membaca buku-buku yang berkaitan dengan seksualitas sejak ia masih remaja inilah yang memengaruhi psikis dari karakter Humbert hingga ia beranjak dewasa. 2) Analisis Karakter Tokoh Utama dan Gambaran Kehidupan Pengarang dalam Novel David Copperfield Karya Charles Dickens yang diteliti oleh Rizky Tungga Takumansang Telleng tahun 2016, Universitas Sam Ratulangi, Manado. Berdasarkan hasil penelitian yang Rizky lakukan, yaitu tokoh David Copperfield, Charles Dickens menggambarkan kehidupan tokoh David Copperfield dari masa kecil hingga dewasa, tokoh utama David merupakan pribadi yang tekun, tegar, polos, pekerja keras, romantik, setia, dan penyayang. Tokoh utama mengajarkan bahwa hidup harus tetap tegar, dan kuat menghadapi setiap persoalan yang akan datang dalam kehidupan selalu bekerja keras untuk dapat memperoleh apa yang diinginkan. Melihat perbedaan hasil penelitian yang mereka lakukan, maka penelitian terhadap novel harus digalakkan dan diajarkan pada siswa di sekolah pada saat ini dan yang akan datang. Menurut Djojosuroto, Kinayati dan Noldy Pelenkahu (2009: 43) novel merupakan struktur bermakna. Novel tidak sekadar merupakan serangkaian tulisan yang menggairahkan ketika dibaca, tetapi struktur pikiran yang tersusun dari unsur-unsur padu. Novel kebalikan dengan cerpen yang bersifat memadatkan, novel cenderung bersifat meluas dalam penceritaannya, novel biasanya menggambarkan pengalaman kehidupan manusia dan manusia dijadikan objek cerita yang disertai dengan konflik, sehingga menyebabkan perubahan jalan hidup si tokoh yang ditampilkan.

H.B Jassin (1985: 78) mengatakan bahwa novel menekankan tentang kehidupan manusia yang ditandai dengan adanya konflik-konflik yang menyebabkan terjadinya perubahan jalan hidup tokohtokohnya. Perubahan jalan hidup tokoh tidak hanya diakhiri dengan keberhasilan atau kegagalan, kebahagiaan atau kesedihan, tetapi juga cara bersikap dan kepribadian tokoh, sedangkan Wellek dan Warren (1993: 283) mengatakan "novel" adalah mengacu pada realitas yang tinggi dan psikologi yang lebih mendalam.

Menurut Sagala (2009: 61) pembelajaran adalah membelajarkan siswa menggunakan asas pendidikan maupun teori belajar yang merupakan penentu utama keberhasilan pendidikan. Pembelajaran merupakan proses komunikasi dua arah, yaitu melibatkan guru dan siswa, sedangkan pada Undangundang Sistem Pendidikan Nasional No.20 Tahun 2003. Pembelajaran adalah suatu proses yang dibangun oleh guru untuk mengembangkan kreativitas berpikir yang dapat meningkatkan kemampuan berpikir 
siswa, serta dapat meningkatkan mengonstruksi pengetahuan baru sebagai upaya meningkatkan penguasaan yang baik terhadap materi pelajaran. Seperti halnya pembelajaran sastra. Tujuan pembelajaran sastra pada siswa di sekolah, yaitu 1) menguasai sejumlah konsep dan wawasan teoretis tentang sastra sebagai karya seni dan tentang metodologi penelitian atau pembahasan sebuah karya sastra, baik intrinsik maupun ekstrinsik, 2) mampu menerapkan secara kritis konsep dan wawasan teoretis itu untuk memberikan, mengapresiasi, dan menafsirkan fenomena sastra sebagai karya fiksi, dan 3) belajar menghargai manusia dan nilai-nilai kemanusiaan.

Selain itu, membaca sastra perlu digalakkan untuk menumbuhkembangkan siswa untuk meningkatkan kegiatan menikmati dan memanfaatkan karya sastra untuk memperluas wawasan, memperhalus budi pekerti, meningkatkan pengetahuan berbahasa dalam rangka penulisan karya ilmiah atau menulis kreatif, menghargai, membanggakan sastra sebagai khasanah budaya dan intelektual manusia, serta mampu memberikan penghargaan terhadap hasil cipta pengarang. Atas dasar uraian di atas, maka peneliti akan menganalisis karakter tokoh utama pada novel Di Bibirnya Ada Dusta karya Mira Wijaya dan Implikasinya terhadap Pembelajaran Bahasa Indonesia.

\section{Metode}

Metode yang digunakan untuk meneliti karakter tokoh utama dalam novel Di Bibirnya Ada Dusta karya Mira Wijaya, yaitu metode deskriptif kualitatif. Metode deskriptif kualitatif adalah suatu model penelitian yang menggunakan teknik-teknik data yang dianalisis. Menurut Moleong (2007) penelitian kualitatif merupakan penelitian yang menekankan pada persoalan kedalaman (kualitas) data bukan banyaknya data. Metode ini lebih menekankan pada penyelesaian masalah yang nyata. Pada tahap akhir ditarik asumsi yang didasarkan dari data yang ditemukan (Lie, 2002), dan dalam penelitian juga menekankan pada kajian kritis terhadap berbagai sumber pustaka. Untuk mengumpulkan data peneliti terlebih dahulu membaca novel secara cermat, menandai dan memindahkan temuan-temuan penelitian ke dalam dokumen data. Fokus penelitian adalah karakter tokoh utama, sedangkan subfokus penelitian mengacu pada karakter tokoh utama yang berkaitan dengan aspek analitik dan dramatik. Oleh karena itu, peneliti menekankan kedalaman penghayatan terhadap interaksi antarkonsep yang sedang dikaji secara empiris dengan menggunakan kata-kata.

\section{Hasil dan Diskusi}

Pada bagian ini peneliti akan menjelaskan hasil temuan karakter tokoh utama dari aspek analitik dan dramatic, serta implikasinya terhadap pembelajaran bahasa Indonesia. Tokoh utama dalam novel ini, yaitu Ray dan Roy. Ray dan Roy merupakan saudara kembar. Mereka hidup tidak bersamaan. Ketika orang tuanya bercerai Ray diasuh oleh ayahnya di Jakarta, sedangkan Roy diboyong ibunya ke Australia. Dalam pengasuhannya tentu berbeda. Ray dibesarkan dengan cara keras, sedangkan Roy diasuh dengan cara santai. Berikut cuplikan isi dari novel tersebut. Ketika ayahnya yang mengidap penyakit hati yang cukup berat menyuruh Ray memikat hati putri mitra bisnisnya untuk menyelamatkan perusahaannya dari ambang kehancuran, Ray tidak dapat menolak. Dia terpaksa minta tolong pada saudara kembarnya, Roy untuk sementara waktu bertukar identitas. Dan pertukaran itu bukan tanpa masalah.

Persoalannya Ray, yaitu mempunyai selera menyimpang. Dia seorang gay yang sudah memiliki teman sehidup semati. Sementara Roy yang berganti-ganti pacar seperti berganti HP, tidak tahan dikelilingi wanita-wanita cantik tanpa mempermainkan mereka. Ketika seorang gay dikejar-kejar wanita sementara seorang lady killer dianggap pria tak berbahaya, berhamburanlah dusta demi dusta untuk menyelamatkan permainan mereka. Dan korban-korban pun berjatuhan karenanya. Oleh karena itu, temuan-temuan kalimat yang merujuk pada tindak-tanduk kedua tokoh utama ini dapat dilihat di bawah ini!

\section{Data Karakter Tokoh Ray}

\section{Aspek Analitik}

Serius

"Aku serius, men!"

"Kapan sih Ray Putra Fajar pernah nggak serius? Hlm. 9 


\section{Analisis}

Pada kutipan di atas menunjukkan bahwa Ray benar-benar menegaskan pada Roy terkait dengan bantuan padanya.

"Kami sudah nekad, Roy. Bagaimanapun kami sudah berjanji akan hidup bersama. Tidak peduli tidak ada yang menikahkan kami yang penting kami saling mencintai”. Hlm.248

Analisis

Kalimat ini menjelaskan pada Roy, walaupun papanya tidak mau menikahkan Ray dengan Bondan. Ray tetap akan menikahinya, karena Ray benar-benar mencintainya sehidup semati.

Tidak, Ray, jangan!"

"Menikahlah dengan Yessy, Roy," pinta Ray lirih demi aku dan papa. Hlm.249.

Analisis

Dalam percakapan dengan Roy, Ray meminta Roy untuk menikahi Yessy, karena Ray tidak mencintai seorang perempuan, melainkan dia senang dengan satu jenisnya.

“Aku akan minta maaf pada papa. Dan menjelaskan semuanya. Jika papa hendak mencoret namaku dari surat warisnya sekalipun, aku rela.

"Ini bukan hanya soal warisan saja, Ray!Ini soal perasaan. Kamu sudah memikirkan bagaimana perasaan Yessy? Dia dipermalukan ketika rencana pernikahan batal karena istri calon suaminya datang menuntut haknya! Sekarang pernikahannya gagal lagi karena calon suaminya lari dengan seorang pria! Kamu jangan Cuma memikirkan dirimu sendiri, Ray!

"Kalau begitu, tolonglah aku sekali lagi, Roy". Sekarang Ray membuka matanya, dan matanya yang berkaca-kaca menatap dengan penuh permohonan. Hlm. 249

Analisis

Kalimat di atas merupakan ungkapan dari seorang Ray yang rela tidak mendapatkan bagian harta dari papanya. Hal ini semata-mata hanya untuk bersanding dengan Bondan bukan yang lainnya.

"Aku akan mengejarnya ke manapun ia pergi. Hanya dengan dia. Aku ingin menikmati hidupku yang kedua ini Roy. Jika kamu pernah merasakan hampir mati, kamu tahu berapa berharganya hidup ini”. Hlm. 259

Analisis

Kutipan di atas. Ray mempertegas pada Roy bahwa keinginannya untuk mencari Bondan ke mana pun ia pergi akan Ray wujudkan demi memanfaatkan hidupnya yang kedua kalinya.

"Rasanya aku sudah pasrah, Roy. Dan aku sudah memilih jika pilihanku keliru, akan kujalani apa pun hukumannya. Aku akan pergi mencari Bondan dan aku sudah memutuskan untuk menemaninya. Kupikir sekaranglah saatnya aku menentukan jalan hidupku sendiri, dan aku berhak melakukannya. Hlm. 278

Analisis

Kutipan kalimat di atas tampak jelas, bahwa keinginan Ray sudah bulat walaupun ia tahu itu merupakan tindakan yang keliru apalagi kalau dikaitkan dengan agama jelas perbuatan mencintai sesama jenis dilarang agama, hal ini disebabkan karena Ray benar-benar sudah terlalu cinta pada 
Bondan. Oleh karena itu, ia akan melakukan jalan hidupnya sendiri tanpa mendengarkan nasihat orang tua maupun saudaranya.

Tekad Ray tidak digoyahkan lagi, dia pergi setelah memohon ampun pada ayahnya, dengan hanya membawa dua buah koper miliknya, dia berangkat ke Palembang untuk mencari Bondan. Hlm. 279

Analisis

Kutipan kalimat di atas, menggambarkan niatnya yang kuat untuk mencari sang kekasih, yaitu Bondan sampai ke Palembang Sumatera Selatan.

\section{Pembohong}

Ray hanya mengangguk, karena yang akan berangkat besok bukan dia. Dia masih tetap tinggal di sini. Entah sampai berapa lama. Sampai Roy dapat meyakinkan papa. dia sudah berhasil memikat hati gadis itu. Hlm. 22

Analisis

Ray berusaha berbohong kepada ibunya. Padahal yang akan pulang ke Jakarta adalah Roy. Roy diminta Ray untuk menggantikan dirinya agar Roy dapat meyakinkan papanya kalau ia sudah dapat memikat gadis itu.

Tidak sulit membohongi ayah dan saudara-saudara tirinya di Jakarta. Sejak masuk fakultas kedokteran ia sudah tinggal di tempat kos di belakang Universitasnya. Tentu saja alasannya supaya dekat ke kampus, padahal alasannya Cuma satu, Bondan. Hlm. 25

Analisis

Ray membohongi papanya dan saudara tirinya. Sejak masuk fakultas kedokteran Ray tinggal di kos belakang kampus tempat ia kuliah, agar selalu dekat dengan orang yang dicintainya, yaitu Bondan.

\section{Aspek dramatik}

Fisik

Mula-mula Ray tidak pernah berniat untuk meninggalkan apartemen Roy. Apalagi untuk pergi ke Mebourne bersama Richard. Ia memang menyukai pria itu. Ray gagah, ganteng, atletis, macho dan menarik, tetapi bagaimanapun fisik Ray, Ray tidak pernah menyukai perempuan. Hlm. 121

Analisis

Kutipan kalimat di atas menggambarkan fisik Ray yang gagah, ganteng, atletis, macho, dan menarik. Tetap saja Ray tidak menyukai lawan jenisnya.

Kondisi Ray sangat buruk, tetapi dia belum tewas, tubuhnya terjepit di antara kerangka mobilnya dan besi beton yang sangat berat. Dibutuhkan peralatan khususnya untuk mengangkat benda seberat itu, dan mendatangkan peralatan itu membutuhkan waktu yang cukup lama. Ray sudah tidak sadarkan diri, kepalanya terluka parah. Dadanya juga hampir remuk. Perutnya kehilangan banyak darah, sementara pertolongan datang sangat terlambat. Ketika dia tiba di rumah sakit, dokter-dokter yang menolongnya sudah hampir putus asa. Prognosisnya sangat buruk.

"Pendarahan efidural, hemotoraks, dan akut abdomen ketiganya dapat menewaskannya. Kata dokter yang memeriksanya. Ray harus di operasi saat itu juga. Tetapi tidak seorang dokter pun dapat menjamin keselamatannya, lukanya sangat parah, dan kehilangan banyak darah. Hlm. 206 
Analisis

Kutipan kalimat di atas menggambarkan kondisi fisik Ray saat ia mengalami kecelakaan. Ia kritis dan terluka parah. Sampai-sampai dokter pesimis atas keberhasilan dalam menanganinya.

Keadaan Ray sungguh memilukan. Hampir seluruh kepalanya yang sudah digunduli ditutup dengan perban. Hanya mata, hidung dan mulutnya yang tampak itu pun masih mengerikan untuk dilihat karena alat bantu penafsiran yang dipasang di sana. Dadanya terbuka juga dibalut kencang dengan perban karena tulang-tulang rusuknya yang patah akan membuat Ray sangat kesakitan setiap kali dia menarik napas kacau dia sadar nanti. Kaka bekas operasi di dada juga sudah dijahit dan dibalut rapi. Di samping melekat pelana monitor fungsi-fungsi vital tubuhnya menimbulkan bunyi monoton yang menegangkan.

Kantung urine yang dihubungkan dengan kateter, kantong drainase yang berisi sisa-sisa darah dan cairan tubuh tampak bergantungan di sisi ranjang. Menerbitkan rasa iba dan ngeri bagi orang awam yang melihatnya. Hlm. 223

\section{Analisis}

Kutipan di atas masih menggambarkan kondisi dan fisik Ray yang cukup parah. Seolah-olah Ray tak panjang umur mengingat kondisinya sudah begitu remuk. Di sini kekuasaan Allah yang bisa berkehendak mau meninggal atau hidup sehingga kita dapat mengambil hikmah dari kejadian itu. sesungguhnya segala sesuatu yang terjadi karena Allah.

\section{Data Karakter Tokoh Roy}

\section{Aspek Analitik}

\section{Pembosan}

Roy seorang pembosan dan gemar mencicipi sesuatu yang berbeda seperti dia mencicipi aneka masakan ibunya. Dia bergonta-ganti pacar seperti bertukar ponsel dan dia sudah bertekad tidak akan menikah sebelum bertemu dengan seorang wanita yang mirip ibunya. Hlm. 20

Analisis

Kutipan kalimat di atas menggambarkan sosok Roy yang playboy. beda dengan Ray yang lebih menyukai sesama jenis. Roy memiliki idealism tinggi, walaupun sering bergonta-ganti pacar. Roy tetap ingin mendapatkan pendamping yang mirip dengan ibunya.

Dia masih berganti-ganti memacari gadis-gadis yang datang dan perganti -ganti gadis-gadis yang datang dan pergi dalam hidupnya. Tetapi seperti yang dikatakan kepada Natalia, tidak seorang pun diundang masuk kehatinya. Hlm. 312

Analisis

Kutipan kalimat di atas Roy masih bersikukuh. Walau banyak wanita yang silih berganti mendekati Roy dan dipacarinya, tapi ia tetap mencari seperti sosok ibunya.

\section{Humoris}

Memang humor baginya merupakan santapan sehari-hari. Dia senang berkelakar suka menjaili teman. Sering teman-teman gadisnya tidak tahan menghadapi keisengan. Tetapi anehnya justru sifatnya yang humoris itu menambah nilai plus di mata gadis-gadis. Hlm. 20

Analisis 
Kutipan kalimat di atas, secara jelas Roy berbeda karakternya dengan Ray. Roy lebih familier, rilek, dan suka bercanda. Maka, tak heran kalau ia disenangi banyak wanita.

Roy sendiri tak tahu, yang jelas, dia tumbuh dalam sebuah keluarga yang humoris. Tidak kaya, tetapi bahagia, karena itu sifatnya pun menyenangkan. Dia humoris, santai tidak memusuhi lingkungan, selalu menganggap enteng semua masalah. Hlm. 33

Analisis

Kutipan kalimat di atas masih menggambar sosok Roy yang benar-benar menyenangkan, Dia menyadari walaupun dia dibesarkan bukan dari keluarga yang kaya raya, dia enjoe. Jadi, Raoy menganggap semua kehidupan enak-enak saja. seolah tak ada beban.

\section{Pemberani}

Roy tidak merasa penyamarannya sebagai beban yang berat atau menakutkan. Dia sama sekali tidak merasa tegang. Dia malah menganggapnya sebagai selingan yang menyenangkan. Kalau bukan tantangan yang membangkitkan semangat. Hlm.33

Analisis

Kutipan kalimat di atas Roy tetap menikmati penyamaran menjadi Ray tidak menjadi beban bagi dirinya. justru ia menganggap hal ini menjadi tantangan yang menyenangkan.

\section{Penghayal}

Siang malam Roy berdebat dengan perasaannya sendiri. Dia menginginkan Natalia. Tetapi gadis itu sudah tidak mungkin diraihnya lagi. Sementara dihadapkannya berdiri sorang gadis lain, gadis yang hebat, setia, dan teguh cintanya. Konsekuensinya dengan janjinya. Yang tidak peduli sudah menjadi apa calon suaminya. Dia tetap akan menikahinya. Sementara di belakangnya sana, terpuruk dua orang laki-laki tua yang pasti sangat menderita kalau pernikahannya Roy dan Yessy dibatalkan. Ayahnya sedang sakit, dan ayah Yessy yang pasti juga sangat sedih.

Bukan hanya sedih, tetapi kecewa, malu kalau pernikahan anaknya dibatalkan lagi. Di mana lagi harus ditaruh mukanya? Hlm. 26

Analisis

Kutipan kalimat di atas, Roy memikirkan dampak, jika tidak menikahi Yessy apa yang akan terjadi. Dua orang tua pasti sedih dan kecewa. Apalagi ayah Roy yang sedang sakit pasti hatinya hancur memikirkannya.

Roy menyeringai geli, dia membayangkan bagaimana malam pertama mereka nanti, sampai bosan Yessy menunggu, Ray belum menyerangnya juga. Ketika Yessy mencoba merangsang gairahnya dengan gaun malamnya yang seksi, suaminya malah menutupi mukanya dengan bantal! ha... ha... ha.... Hlm. 221

Analisis

Kutipan kalimat di atas Roy membayangkan jika Ray menikah dengan Yessy apa yang terjadi, ketika si wanita mencoba merangsang suaminya, Ray justru merasa takut kalau-kalau diserang oleh istrinya. Tentu ini beralasan karena Ray bukan tipe laki-laki yang menyukai wanita, ini justru terbalik, Ray seorang gay. 


\section{Pembohong}

Dari bibirnya yang bersimbah dusta meluncur kata-kata yang begitu tulus. Kata-kata yang lahir dari jiwa yang dewasa. Diambang tiga puluh tahun, ternyata Roy telah meraih kedewasaan dan kematangan jiwanya. Sayangnya, dia belum memiliki kebijaksanaan untuk memilih wanita yang tepat untuk mendampingi hidupnya. Karena wanita yang tepat untuknya kini tinggal baying-bayang. Hlm. 314

Analisis

Kutipan kalimat di atas, menggambarkan sifat Roy yang juga pembohong, kata-kata dusta yang disampaikan ke wanita-wanita dengan tulus itu tidak menjadi kenyataan, ini dapat dilihat dari usianya yang sudah mendekati tiga puluh tahun, ia belum memiliki istri.

\section{Aspek dramatik}

Fisik

Roy memang memiliki semua yang didambakan seorang gadis pada diri seorang pria. Dia tampan, tubuhnya atletis, sikapnya gagah, penampilannya macho, dan otaknya tidak tulalit. tentu saja, kalau tulalit, masa dia bisa jadi dokter hewan pada usia dua puluh empat tahun. Hlm. 20

Analisis

Kutipan kalimat di atas mengungkapkan, bahwa Roy ganteng, berpenampilan menarik, dan bentuk tubuhnya yang kekar, serta cerdas, sehingga di usia dua puluh empat tahun ia sudah menjadi dokter.

\section{Implikasi terhadap Pembelajaran Bahasa Indonesia}

Penelitian karakter tokoh utama pada novel Di Bibirnya Ada Dusta karya Mira Wijaya memiliki implikasi terhadap dunia pendidikan khususnya pembelajaran bahasa dan sastra Indonesia. Pada kurikulum 2013, kelas XII di silabus KD 3.9 dan 4.9, yaitu menganalisis isi dan kebahasaan novel serta merancang novel atau novelette dengan memerhatikan isi dan kebahasaan. Indikator yang diharapkan dari KD ini, yaitu siswa dapat menemukan unsur intrinsik dan unsur ekstrinsik, dapat menyusun novel berdasarkan rancangan, mempresentasikan, mengomentari, dan memperbaiki unsur-unsur intrinsik dan kebahasaan novel dan hasil penulisan novel. Oleh karena itu, pembelajaran sastra mengenai analisis novel dapat diaplikasikan oleh pendidik atau guru kepada siswanya dengan tujuan untuk membangun kreativitas siswa dalam mengapresiasikan karya sastra. Salah satu keunggulan novel sebagai materi ajar, yaitu siswa mudah dalam mempelajari sesuai dengan kemampuan masing-masing. Apabila kemampuan pemahaman siswa dalam mempelajari novel berbeda-beda, pendidik atau guru dituntut untuk menggunakan strategi pembelajaran yang cocok agar siswa senang menerima pelajaran tersebut. Sebagai contoh pembelajaran novel bisa disajikan dalam video. Kelebihan melihat video, siswa dapat menemukan langsung pelakunya, karakternya, alurnya, amanatnya, dan sebagainya.

\section{Simpulan}

Berdasarkan hasil penelitian dari Novel Di Bibirnya Ada Dusta karya Mira Wijaya yang terkait dengan aspek analitik dan dramatik dua tokoh utama, yaitu Ray dan Roy. Ray dan Roy merupakan anak kembar. Mereka dibesarkan oleh orang tuanya yang berbeda tempat. Setelah orang tua mereka berpisah, Ray diasuh ayahnya di Jakarta, sementara Roy diasuh ibunya di Australia. Dengan perbedaan cara pengasuhan sehingga membentuk watak atau karakter yang berbeda pula. Ray tumbuh menjadi seorang gay dan Roy menjadi seorang yang demokratis. Sikap Ray dari aspek analitik, yaitu serius dan pembohong, sedangkan sikap dramatik Ray digambarkan memiliki fisik bertubuh atletis, macho, ganteng, tampan, dan cerdas, sedangkan Roy memiliki fisik mirip dengan Ray jika dilihat dari segi dramatik, yaitu ganteng, macho, cerdas, bertubuh atletis, dan penghayal, sedangkan aspek analitik, yaitu pembosan, penghayal, pemberani, dan pembohong. Dari hasil penelitian ini akan digunakan untuk menumbuhkembangkan siswa untuk meningkatkan kegiatan menikmati dan memanfaatkan karya sastra, 
memperluas wawasan, memperhalus budi pekerti, meningkatkan pengetahuan berbahasa dalam rangka penulisan karya ilmiah atau menulis kreatif, menghargai, membanggakan sastra sebagai khasanah budaya dan intelektual, memberikan penghargaan terhadap hasil cipta pengarang, memberikan pengajaran bahasa dan sastra Indonesia, mendorong siswa untuk meningkatkan penghayatan, mampu mengapresiasi, serta mengenalkan sikap atau tindak-tanduk tokoh yang digambarkan oleh pengarang

\section{Ucapan Terima Kasih}

Peneliti mengucapkan terima kasih kepada semua pihak yang telah membantu dalam proses penulisan artikel ilmiah ini.

\section{Daftar Rujukan}

Arikunto, Suharsimi, dkk. Penelitian Tindakan Kelas Edisi Revisi. Jakarta: PT Bumi Aksara, 2002. Print Djojosuroto, Kinayati dan Noldy Pelenkahu. Apresiasi Pembelajaran Prosa. Yogyakarta: Pustaka Book Publiser, 2009. Print

Lie. Cooperatif Learning. Jakarta: Grasindo, 2002. Print

Mahsun. Metode Penelitian: Tahapan Strategi, Metode dan Tekniknya. Jakarta: Raja Grafindo Persada, Moleong. Metodolgi Penelitian Kualitatif. Bandung: PT Remaja Rosdakarya, 2004. Print

Semi, M. Atar. Anatomi Sastra. Padang: Angkasa Raya, 1988. Print

Sudjiman, Panuti. Memahami Cerita Rekaan. Jakarta: Pustaka Jaya, 1992. Print

Sumarjo, Yakub. Apresiasi Sastra. Jakarta: Gramedia, 1997. Print

Undang-undang Sistem Pendidikan Nasional No.20 Tahun 2003. Print

Wellek dan Warren.Teori Kesusastraan. Jakarta: Gramedia, 1993. Print

Wijaya, Mira. Di Bibirnya Ada Dusta. Jakarta: Gramedia, 2003. Print

Yassin, H.B. Tiga Penyiar Daerahnya. Jakarta: Gunung Agung, 1985. Print

Jeyklin Byi, Jein. Skripsi Analaisis Karakter Tokoh Utama dalam Novel Lolita KaryaVladimir Nabokov.Universitas Sam Ratungi Manado, 2016. Print

Takumansang Telleng, Rizky Tungga. Skripsi Analisis Karakter Tokoh Utama dan Gambaran Kehidupan Pengarang dalam Novel David Copperfield Karya Charles Dickens.Universitas Sam Ratulangi Manado, 2016. Print 